\title{
PROPOSTA DE IMPLEMENTAÇÃO ESTRATÉGICA NA GESTÃO ADMINISTRATIVA: ESTUDO DE CASO NA EMPRESA SALÃO ELLEN NASCIMENTO
}

\section{ARTIGO ORIGINAL}

SANTOS, Janaina Auxiliadora Tavares dos ${ }^{1}$, FERNANDES, Emanuel Nascimento², SILVA, Mauricio Luciano Batista da $^{3}$, ROBERTO, José Carlos Alves ${ }^{4}$, ALMEIDA, Victor da Silva ${ }^{5}$, EITE, Ygor Geann dos Santos ${ }^{6}$

SANTOS, Janaina Auxiliadora Tavares dos. Et al. Proposta de implementação estratégica na gestão administrativa: estudo de caso na empresa Salão Ellen Nascimento. Revista Científica Multidisciplinar Núcleo do Conhecimento. Ano 06, Ed. 11, Vol. 12, pp. 113-133. Novembro de 2021. ISSN: 2448-0959, Link de acesso: https://www.nucleodoconhecimento.com.br/administracao/empresa-salao-ellen, DOI: 10.32749/nucleodoconhecimento.com.br/administracao/empresa-salao-ellen

\section{RESUMO}

O presente artigo aborda um estudo de caso realizado no Salão Ellen Nascimento, uma empresa de pequeno porte, que atua na área de beleza e estética, localizada em Manaus/AM e que apresentava grandes dificuldades na área administrativa. A partir de estudos preliminares realizados na empresa, estabeleceu-se a necessidade de aprofundar os estudos relativos à gestão do negócio, e, nesse contexto, levantouse a questão norteadora: Como a implementação de técnicas administrativas e tecnologias de gestão podem ser utilizadas em uma microempresa para seu melhor

\footnotetext{
${ }^{1}$ Graduanda do curso de Administração.

${ }^{2}$ Graduando do curso de Administração.

${ }^{3}$ Graduando do curso de Administração.

${ }^{4}$ Orientador. Mestre em Engenharia de Produção. Especialista em Logística Empresarial. Graduado em Administração com Ênfase em Marketing.

${ }^{5}$ Coorientador. Mestre em Engenharia de Processos. Pós-Graduando em Neuropsicopedagogia Institucional. Especialista em Gestão Estratégica de RH. Graduado em Administração e Pedagogia.

${ }^{6}$ Coorientador. Mestre em Ciência e Engenharia de Materiais. Especialista em Engenharia da Qualidade e Seis Sigma. Graduado em Tecnologia em Gestão da Qualidade.
}

RC: 101963

Disponível em: https://www.nucleodoconhecimento.com.br/administracao/empresasalao-ellen 
desenvolvimento? Este estudo de caso tem como objetivo geral, desenvolver alternativas para estruturar o negócio a partir da capacitação da base administrativa e financeira e usar a tecnologia como forma de desenvolver a organização nos aspectos operacionais, financeiros e de marketing. A pesquisa se caracteriza como qualitativa, com fins exploratórios e se realiza por meio do estudo bibliográfico. Como resultado, preparou-se um pacote de ações interventivas voltadas para capacitação do empreendedor, que compreendem as técnicas financeiras e práticas de gestão de equipes em projetos de Co-work. O plano também contempla o uso de recursos de software como forma de estimular uma melhora no desenvolvimento da organização, tendo em vista a praticidade, entendimento e facilidade de gestão da empresa estudada. Utilizou-se a ferramenta de qualidade $5 \mathrm{~W} 2 \mathrm{H}$ para estabelecer as etapas de introdução e cronograma das ações interventivas. Deste modo, o estudo atende seus propósitos ao estabelecer um conjunto de ações que pretendem solucionar os problemas identificados no diagnóstico organizacional.

Palavras-chave: Microempreendedor, técnicas administrativas, tecnologia.

\section{INTRODUÇÃO}

Esse artigo se trata de um estudo de caso na empresa Salão Ellen Nascimento, uma microempresa que atua no ramo da beleza e estética, que tem como segmento a modalidade CoWork, possibilitando, assim, o trabalho coletivo de vários profissionais liberais que atuam no ramo da beleza, como manicures, esteticistas, cabeleireiros, entre outros.

Sabe-se que o pouco conhecimento dos microempreendedores em administração faz com que muitas microempresas passem por dificuldade de gestão, por falta de organização, de controle financeiro e de planejamento. Ao observar o salão Ellen Nascimento, foi diagnosticado que a administração do salão é muito primitiva, pois ainda realiza o controle de dados por meio de cadernos e comandas, o que afeta 0 crescimento da empresa. 
O objetivo desta pesquisa é apresentar métodos de treinamento para a utilização de ferramentas mais atuais e técnicas administrativas. Com base nisso desenvolveu-se a questão norteadora: Como a implementação de técnicas administrativas e tecnologias de gestão podem ser utilizadas em uma microempresa para seu melhor desenvolvimento?

Este estudo de caso tem como objetivo geral, desenvolver alternativas para estruturar o negócio a partir da capacitação da base administrativa e financeira, e usar a tecnologia como meio de desenvolver a organização no setor operacional, financeiro e de marketing.

O estudo tem como objetivos específicos: a melhoria da administração da empresa por meio da capacitação do gestor, a utilização das ferramentas de gestão, e a aplicação de um software de gestão específico para um salão de beleza. Estas ações visam aumentar a eficiência e praticidade no lançamento de dados, no atendimento do cliente e na interpretação de dados.

Com a aplicação das técnicas sugeridas na empresa, espera-se mais eficiência na administração, a melhora dos empreendedores da gestão financeira, a utilização de ferramentas tecnológicas mais atuais que facilitem a vida do gestor, a utilização do marketing digital para a melhor promoção da empresa e, por fim, a melhoria no atendimento dos clientes com o agendamento e lançamento de serviços, de modo a otimizar a empresa e capacitar os microempreendedores.

\section{FUNDAMENTAÇÃO TEÓRICA}

A fundamentação teórica auxilia na melhor compreensão das informações apresentada no texto e, por meio do estudo do trabalho de autores renomados, que discutiram anteriormente a respeito do problema que será abordado e solucionado no trabalho, proporciona uma base para sustentar as afirmações feitas na pesquisa.

Também conhecido como marco teórico, a fundamentação teórica é a elaboração de uma base de autores que serve de referência para a realização do trabalho com

RC: 101963

Disponível em: https://www.nucleodoconhecimento.com.br/administracao/empresasalao-ellen 
base no tema apresentado, assim como para o embasamento teórico necessário para o desenvolvimento da solução que será proposta e implementada na microempresa, de modo a auxiliar os microempreendedores a desenvolverem uma base técnica administrativa (ALVES, 2013).

É por meio da fundamentação teórica que se apresenta e discute os conceitos, com o auxílio de pesquisas, ideias e opiniões de outros autores, utilizados também para embasar afirmativas e comprovar que elas são verdadeiras. Ela também faz um levantamento de estudos já realizados sobre o tema a ser abordado e, com isso, faz com que o leitor tenha mais compreensão e confiança no artigo e, de modo a chamar atenção para a consistência teórica (SAKAMOTO; SILVEIRA, 2019).

\subsection{ADMINISTRAÇÃO E TECNOLOGIA}

Atualmente, dentro do cenário competitivo em que as microempresas se encontram, a tecnologia é uma das principais ferramentas para quem busca sobreviver, competir e se destacar nesse meio. Ela vem crescendo a passos largos, seja no marketing, com propagandas e divulgações, ou dentro da administração, com avanço das tecnologias. Com a utilização da tecnologia, as tomadas de decisões, o controle financeiro e a visualização da organização como um todo se torna mais profundo e mais específico, o que faz dela uma ferramenta muito eficaz dentro de uma microempresa, que ajuda a prever e evitar erros e auxilia no crescimento e na permanência da empresa no mercado, e por isso a utilização de recursos tecnológicos, como os softwares, é de extrema importância para empresa.

Com a evolução do mercado por meio do avanço da tecnologia, as organizações aprimoram seus produtos, seus processos e, com isso, evoluem o mercado, o que permite que capacidades administrativas cada vez mais aprimoradas sejam empregadas de forma mais eficaz e eficiente dentro de organizações. E com o objetivo de crescimento constante e aprimoramento de suas atividades, as empresas investem $5 \%$ de sua receita em tecnologia, desta forma a organização detêm melhores tecnologias para auxiliar na sua administração e consegue, por um 
período de tempo relativo, uma vantagem competitiva dentro do mercado (BURGELMAN; CHRISTENSEN; WHEELWRIGHT, 2013).

A inovação tecnológica é um dos fatores que proporcionam uma vantagem competitiva às empresas, pois essas tecnologias dão mais eficiência e eficácia aos processos. Dentro do mercado, a tecnologia se mostra ser de grande relevância para todas as organizações, e se tornou uma peça fundamental e indispensável para a sobrevivência delas, pois quase todos os produtos ou processos passam por aparelhos tecnológicos. (BATEMAN; SNELL, 2013).

\subsubsection{A IMPORTÂNCIA DA ADMINISTRAÇÃO EM UMA MICROEMPRESA}

Dados do Sebrae (2020) comprovam que existem 8,9 milhões de micro e pequenas empresas no brasil que contribuem com $27 \%$ do PIB nacional e geram $52 \%$ dos empregos com carteira assinada, e são dados que, com o passar do tempo, só tendem a crescer e aumentar cada vez mais o empreendedorismo no Brasil. Esses dados nos fazem pensar cada vez mais sobre a importância e necessidade de uma boa gestão dentro desses pequenos negócios, pois a taxa de sobrevivência das microempresas, dentro de um período de 5 anos, é de apenas $29 \%$, e essa porcentagem extremamente baixa se dá pela falta de capacitação e conhecimentos fundamentais de administração, que auxiliam e prolongam a existência de seus negócios. O salão de estética Ellen Nascimento, localizado no Amazonas, é uma microempresa classificada como $\mathrm{MEI}$, que atua em um dos segmentos que mais cresce na região e que mais tem problemas com administração.

Dados do Sebrae (2020) apontam que existem 80.402 mil empresas em funcionamento dentro do Amazonas, das quais 30.987 (38,40\%), são classificadas como micro e pequenas empresas, o que representa um dado muito relevante para economia do estado. O que causa preocupação a respeito da administração dessas microempresas é que cerca de $65,69 \%$ delas estão inadimplentes, uma taxa extremamente alta para organizações que muito contribuem para a economia de um

RC: 101963

Disponível em: https://www.nucleodoconhecimento.com.br/administracao/empresasalao-ellen 
estado. Buscar soluções e capacitar os microempreendedores é essencial para o desenvolvimento do mercado e da economia, tanto no âmbito estadual quanto no nacional.

Existem muitas barreiras para os microempreendedores na caminhada para abrir seu próprio negócios, seja a falta de conhecimento técnico-científico, a falta de recursos financeiros para apoiar seu empreendimento, ou uma competitividade esmagadora, gerada por grandes empresas que visam cada vez mais aumentar seus lucros, por meio da adoção de técnicas e tecnologias cada vez mais avançadas e do aperfeiçoamento de seus produtos ou serviços, o que aumenta sua participação e influência dentro do mercado e o torna cada vez mais competitivo. Por tanto, é necessário desenvolver e fornecer aos microempreendedores técnicas que apresentem uma linguagem e metodologias mais objetivas, que auxiliem no desenvolvimento, amadurecimento e tomadas de decisões, e auxiliar na implantação de ferramentas tecnológicas que possam automatizar as organizações, para que continuem a agregar valor e a contribuir para a economia de seu país. (RODRIGUES, 2014).

Sabe-se que o número de empreendedores no Brasil é um dos maiores do mundo, um número que aumenta a cada ano e passa a ser cada vez mais relevante para economia do país, que gera cada vez mais empregos às classes mais baixas e oferece aos colaboradores oportunidades de voltarem ao mercado de trabalho. Porém, muitos desses empreendimentos ainda atuam sem regularização e não cumprem com seus deveres para o estado, o que faz com que a importância do administrador não esteja somente em gerir, mas também em regulamentar essas organizações (SENHORAS, 2021).

\subsubsection{CONTROLE FINANCEIRO}

A maioria dos empreendimentos são criados por necessidade, ou seja, pela falta de emprego ou insatisfação, e isso nos dá um cenário de baixa aplicação ou inexistência de técnicas de administração, portanto, quando os 
microempreendedores iniciam um negócio em qualquer segmento, a falta de organização e, principalmente, o descontrole financeiro são responsáveis pelo fechamento desses negócios. A falta de organização financeira e o descontrole de gastos dentro de uma microempresa é, sem dúvidas, uma sentença de morte para a empresa, pois o conhecimento técnico de finanças é extremamente importante para uma microempresa se desenvolver.

O controle financeiro deve ser o braço direito do empreendedor, pois é sempre com a situação econômica de seu negócio em vista que se deve tomar a maioria das decisões relacionadas à empresa. Controlar finanças não tem a ver somente com o caixa ou com o dinheiro da empresa, mas também com o controle de vendas e com a entrada e saída de produtos em estoque, pois não perder ou desperdiçar dinheiro é tão importante quanto captar recursos. A falta de pessoas capacitadas para a gestão de finanças é um problema muito recorrente dentro das organizações, já que ter um conhecimento para gerir a parte financeira requer muita disciplina (BARBOSA; REIS, 2021).

Para uma boa gestão financeira, existem ferramentas que dão base e auxiliam na gestão das finanças e que também auxiliam o administrador no desenvolvimento de um plano de negócios que visa que direcionar a empresa para o caminho mais vantajoso, como o fluxo de caixa, utilizado para controlar entrada e saídas de recursos. Essas ferramentas são usadas constantemente e vão se tornando cada vez mais complexas de acordo com o desenvolvimento da empresa, e por isso se ressalta a importância de se iniciar cedo uma boa gestão financeira (CONTROLLE, 2014).

\subsubsection{MARKETING DIGITAL DE MICROEMPRESAS}

Grandes empresas se tornam mais influentes por meio de um marketing bem aplicado, seja em jornais, rádios ou televisão, o importante é que o meio de divulgação escolhido tenha um grande alcance que exiba os produtos ou serviços para um grande público. Mas uma das grandes vantagens das microempresas é 
estar cada vez mais próxima de seus clientes, ou seja, elas compreendem melhor as necessidades de seus clientes e as atendem de forma mais efetiva. Isso dá à microempresa uma vantagem competitiva em agregar clientes a seus negócios, mas como achar esses clientes? As redes sociais, sejam sites, blogs ou mídias sociais, acabaram produzindo um nicho extremamente importante para esses microempreendedores, que, por conta dessa alta comunicação, conseguem atender cada vez mais as necessidades de seus clientes, o que também gera a oportunidade de sempre renovar produtos e serviços ou oferecer novidades mais rápido que grandes empresas. Atualmente, por conta de um marketing bem aplicado por meio das mídias sociais, as microempresas têm conseguido mais poder para se destacar e para serem cada vez mais reconhecidas dentro do mercado, que se torna cada vez mais competitivo à medida que o tempo passa.

Os avanços tecnológicos têm tornado o mercado cada vez mais competitivo, e tem permitido que empresas de grande porte se sobressaiam ainda mais no mercado, com processos e produtos cada vez mais automatizados. Junto com os avanços tecnológicos, as redes sociais tiveram um crescimento exorbitante, o que tem dado cada vez mais espaço para microempresas se destacarem no mercado, por meio da utilização de um marketing mais barato e acessível, e com um alcance muito maior que o de outros meios de comunicação, o que possibilita uma competição em pé de igualdade com as grandes empresas, quando o quesito é visibilidade (CHINEM, 2017).

O marketing digital é bem mais do que um tipo de marketing, é um uma consolidação de comércio dentro das plataformas digitais, é o dinamismo e a evolução da sociedade, que muda valores e desejos, que faz com que o marketing digital não se preocupe somente com as vendas ou aquisição de clientes, mas também com o cliente como um ser humano complexo. As microempresas também devem se preocupar em mostrar, por meio do marketing, suas operações, sua visão, sua missão e seus valores, para poder se conectar mais profundamente com o cliente e, assim, criar uma relação mais profunda e duradoura (HERTER; LEAL; SOARES, 2019).

RC: 101963

Disponível em: https://www.nucleodoconhecimento.com.br/administracao/empresasalao-ellen 


\subsection{TECNOLOGIAS NA ADMINISTRAÇÃO}

Os recursos tecnológicos têm se tornado grandes aliados dos administradores nessa era de indústrias mais automatizadas. A complexidade das empresas se tornou algo comum, e até mesmo as microempresas apresentam complexidade em seu gerenciamento, pois, com o mundo completamente globalizado e competitivo, recursos de alto padrão são utilizados desde cedo, para que as empresas não fiquem muito atrás na competição e percam espaço no espaço no mercado.

A administração de uma microempresa, assim como a de uma multinacional, passa pelos mesmos setores, como o setor administrativo, o setor de marketing e o setor financeiro. Portanto, usar a tecnologia auxilia imensamente os setores que precisam se automatizar para melhorar a performance. A utilização de softwares para a melhora do desempenho tem se mostrado cada vez mais necessária em uma microempresa, seja no controle de estoque ou na produção de relatórios, e além de tornar o trabalho mais eficiente e prático, ele também auxilia na tomada de decisão dos administradores (CARVALHO; KUBICA, 2017).

O uso da tecnologia dentro de uma empresa deve satisfazer e aumentar a eficácia da organização, e cabe ao gestor da empresa procurar, desenvolver ou contratar o tipo de tecnologia que mais se adequem ao seu segmento. Portanto, deve-se verificar o plano estratégico da empresa antes de se definir o tipo de tecnologia que será utilizada, pois os setores estão interligados, e a tecnologia deve abranger e auxiliar todas as áreas de uma organização. (HERTER; LEAL; SOARES, 2019).

\subsubsection{SOFTWARE}

Os softwares são recursos desenvolvidos a partir de uma tecnologia que tem a capacidade de auxiliar os administradores nas tomadas de decisões por meio de relatórios, comparações, controle de estoque, entre outros recursos, que dependem exclusivamente do segmento da organização. Para as microempresas, o uso de software é muito importante para a gestão do negócio, já que há inúmeras 
dificuldades para o microempreendedor. O auxílio de um sistema lhe dá uma base para tomar decisões e controlar suas ações, de modo a proporcionar uma visão bem mais ampla e minimizar o número de erros, ou ajustar qual processo ou produto que esteja the dando prejuízo. A pesquisa propõe aplicar um software, chamado AVEC, no Salão de Estética Ellen Nascimento, que auxiliará em vários aspectos a organização

A escolha do software que irá auxiliar a organização é de extrema importância para o administrador, mas é importante ressaltar que o software não dará a solução ou irá eliminar o problema a ser resolvido, o programa irá auxiliar na compreensão de dados, na automatização dos serviços ou em qualquer outro setor que for implantado, mas cabe ao administrador saber interpretar os dados e tomar as melhores decisões para a solução dos problemas ou crescimento da empresa (SERIES, 2017).

Existem muitas vantagens em ter um software para auxiliar o gestor dentro de uma organização, pois os dados que o software pode dar ao administrador são mais concretos e mais específicos, e consegue transformar dados em gráficos para a melhor compreensão do gestor. Também se tem um controle bem mais correto do estoque, com a entrada e a saída dos recursos, o que pode minimizar ou até zerar o desperdício da empresa (MORAES, 2020).

\subsubsection{AVEC}

A AVEC é uma plataforma online que oferece um sistema de gestão especializado em salões de beleza, ela oferece uma série de ferramentas que auxiliam e aumentam a eficiência na gestão de vários salões de beleza. Suas principais ferramentas oferecem auxílio em Marketing, Pagamentos e Gestão de sistemas.

Muitos salões de beleza apresentam problemas com agendamento de clientes. A AVEC, também oferece uma plataforma online e um aplicativo de agendamento, o que elimina completamente a agenda física. Por meio dessa agenda online é 
possível confirmar agendamentos e enviar mensagem para o cliente agendado via WhastApp, para lembrar o cliente do seu agendamento e, desta forma, evitar faltas e encaixes de outros clientes em caso de desistência.

Além disso, a plataforma tem um sistema de gestão financeira e de pagamentos de funcionários, que permite eliminar o fluxo de caixa no caderno. O lançamento da comanda dos funcionários também se torna completamente online, o que facilita a administração financeira e elimina as comandas de papéis, além de apresentar diversos dados que auxiliam nas tomadas de decisões.

\section{MATERIAIS E MÉTODOS}

A escolha de uma metodologia a ser abordada deve-se levar em consideração principalmente qual problema queremos resolver ou quais conhecimentos queremos adquirir, pois não existe uma única metodologia para solucionar vários problemas, existem múltiplos métodos para múltiplas situações. Com base nisso, definiu-se que a metodologia aplicada nesta pesquisa deve estar completamente ligada ao objetivo a ser alcançado, ou seja, uma metodologia que auxilie na melhoria de determinados aspectos dentro de pequenas e microempresas, no desenvolvimento e no crescimento dessas organizações.

Todo tipo de ciência se utiliza de algum tipo de metodologia ao realizar um estudo crítico e analítico a respeito de determinado assunto, mas a metodologia não é uma lista de regras usadas para apresentar ou montar um trabalho científico, a metodologia está mais voltada para estudar, compreender e descrever os métodos, para melhor conduzir uma situação ou resolver um problema (ZANELLA, 2013.)

\subsection{PROCEDIMENTOS METODOLÓGICOS}

Existem muitas formas de adquirir conhecimento, seja por meio de estudos formais ou informais, porém, o conhecimento científico exige fórmulas exatas que apresentem veracidade, e é por ter essa obrigação com a veracidade dos dados que 
os procedimentos metodológicos se tornam tão importantes para uma pesquisa. A metodologia informativa foi a escolhida para a resolução do problema da empresa, de modo a auxiliar os empreendedores de microempresas a se desenvolverem melhor administrativamente.

O procedimento metodológico é o que dá a base para o pesquisador organizar o trabalho e obter os resultados que busca de forma mais objetiva e centrada. Estes procedimentos descrevem como a metodologia irá atuar dentro da empresa e para qual propósito essa metodologia foi criada, uma vez que se sabe que o processo metodológico tem as caraterísticas e segue a mesma linha de raciocínio do problema a ser solucionado ou produto a ser desenvolvido (CAUCHIK et al., 2013)

Os processos metodológicos são definidos a partir do tipo de pesquisa que será realizado e qual método será utilizado para auxiliar na tomada de decisão, além de se basear em conhecimentos que sejam verdadeiros e tenham veracidade (SEVERINO, 2014).

\subsubsection{QUANTO À NATUREZA}

O estudo de caso abordado apresenta uma natureza qualitativa e busca compreender a necessidade dos microempreendedores e suprir suas demandas, para que tenham melhores resultados e permaneçam ativos no mercado, e com base nisso, aplica-se o conhecimento teórico, fundamentado em estudos científicos, na resolução dos objetivos.

Dentro de uma pesquisa de cunho qualitativo há uma obrigação maior em lidar com fenômenos e ser completamente original, para que o conhecimento não fique preso somente aos dados. Entretanto, ele fica sujeito a interpretações de seu autor, pois ambiente $O$ ambiente estudado é uma fonte de dados em que não existe manipulação de dados (DIAS; SANTOS; SOUZA, 2013).

A pesquisa qualitativa está ligada a uma análise subjetiva ou interpretativa do pesquisador, e é muito comum uma pesquisa qualitativa esteja ligada a pesquisa

RC: 101963

Disponível em: https://www.nucleodoconhecimento.com.br/administracao/empresasalao-ellen 
exploratória, pois, dessa forma, se amplia o conhecimento a respeito do fenômeno a ser estudado (CARDANO, 2017).

\subsubsection{QUANTO AOS FINS}

Essa pesquisa se trata de uma pesquisa exploratória, que tem o objetivo de se aprofundar nas técnicas administrativas e nos treinamentos para microempreendedores, pois as micro e pequenas empresas vem crescendo mais a cada ano e geram cada vez mais empregos.

A pesquisa exploratória explora o meio-ambiente e a realidade para ampliar e aprofundar os conhecimentos de determinada área, segmento ou ciência, ela é a base para planejar a pesquisa descritiva (ZANELLA, 2013).

A pesquisa exploratória também auxilia no desenvolvimento e esclarecimento de ideias a respeito de algum fenômeno, ou seja, é uma pesquisa que serve de base para pesquisas mais especializadas, como, por exemplo, a pesquisa experimental (CARVALHO et al., 2019).

\subsubsection{QUANTO AOS MEIOS}

Quanto aos meios, a pesquisa se classifica como um estudo de caso, pois a análise e o aprofundamento são realizados do mesmo modo que em uma pesquisa aplicada, e buscam aplicações práticas para microempreendedores que não conhecem ou não tem acesso a soluções administrativas, para que eles possam continuar atuando e crescendo como organização.

O estudo de caso tem o objetivo de analisar dados coletados sobre uma situação ou grupo, a fim de estudar minuciosamente como solucionar determinada situação, e para que se esclareça o objetivo e auxilie na tomada de decisão ou conjunto de decisões, de modo que o pesquisador possa ter uma boa base de análise, pois não há dados prontos no estudo de caso, cada análise de caso é única, por se tratar de realidades distintas (GERRING, 2019).

RC: 101963

Disponível em: https://www.nucleodoconhecimento.com.br/administracao/empresasalao-ellen 


\subsection{CARACTERÍSTICAS DA EMPRESA: SALÃO E ESTÉTICA ELLEN NASCIMENTO}

A empresa Salão de Estética Ellen Nascimento, localizada na Av. B, Alvorada 1, Manaus - Amazonas, é uma organização que atua na modalidade de prestadora de serviços de beleza, que tem como foco principal o atendimento de mulheres, e é bastante conhecida pelo trabalho com coloração de cabelos loiros, mechas morenas iluminadas e mega hair. Atualmente, o salão conta com um espaço de 7 por 11 metros, e possui uma sala de estética, uma sala de personalização de cabelos, uma pequena sala de química e um espaço no qual trabalham com cabelos e manicure. O salão também conta com 6 secadores de cabelo, 5 chapinhas, 2 babylis, maca de estética, esterilizador, bebedouro, ar-condicionado, lavatório de cabelo, poltronas, espelho grande e um local para tirar fotos. A empresa trabalha na modalidade de coworking e possui 4 colaboradores. O salão trabalha com horário marcado, e o horário de atendimento vai das 08:00 às 22:00.

\section{RESULTADOS E DISCUSSÕES}

A coleta de informações do Salão Ellen Nascimentos ocorreu por meio de uma entrevista oral e por vídeo chamada com a proprietária.

Todo relato fornecido possibilitou o acesso a informações necessárias para que se desse início a construção do diagnóstico organizacional.

O gráfico 01 apresenta o desempenho da área funcional e evidencia os pontos fracos e fortes da empresa. 
Gráfico 1 - Desempenho de área funcional.

\section{Média - Desempenho por Área Funcional}

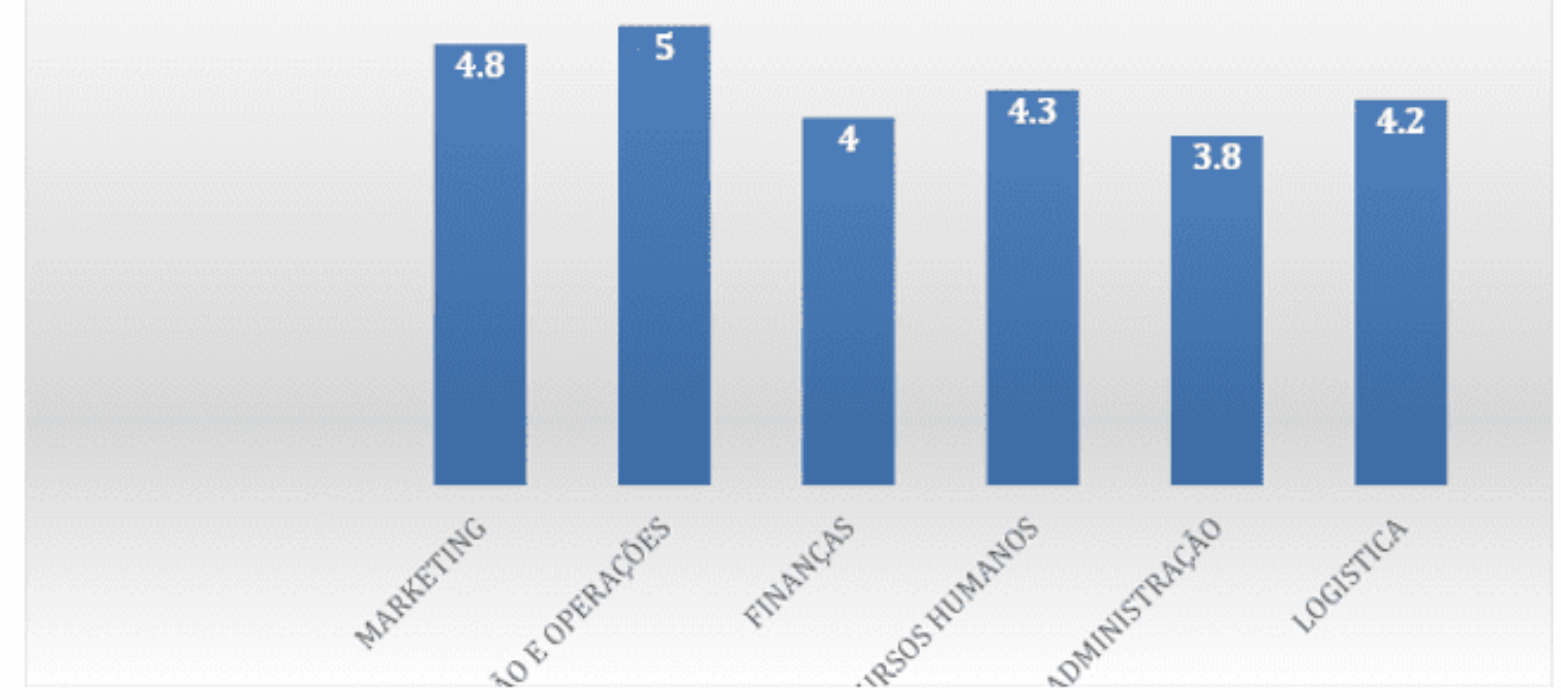

Fonte: Elaborado pelos autores com base na coleta de dados, 2021

De acordo com o gráfico acima, os resultados foram atribuídos em pontuações de acordo com cada setor da organização. Em vista disso, a somatória dos setores possibilitou uma comparação exata entre eles.

Observa-se que as áreas críticas e com os menores índices estão presentes nos setores administrativo e logístico. Em comparação, os departamentos de produção/operações e marketing se apresentam como as áreas mais bem avaliadas.

Contudo, entre os seis setores, o que se encontra como maior risco para a empresa é o departamento administrativo, o que evidencia certa inferioridade em relação aos demais setores. Desta forma, foi concluído que a empresa necessita de soluções urgentes para reverter o seu quadro crítico.

RC: 101963

Disponível em: https://www.nucleodoconhecimento.com.br/administracao/empresasalao-ellen 
Quadro 1 - Sendo 5 o valor máximo (ponto muito forte) e 1 valor mínimo (ponto muito fraco)

\begin{tabular}{|c|c|c|c|c|c|c|}
\hline \multirow{2}{*}{\multicolumn{2}{|c|}{$\begin{array}{l}\text { ÁREA FUNCIONAL } \\
\text { ADMINISTRAÇÃO }\end{array}$}} & \multicolumn{5}{|c|}{ NÍVEL OU GRAU DE AVALIAÇÃO } \\
\hline & & \multirow{2}{*}{$\begin{array}{l}\text { Ponto } \\
\text { muito } \\
\text { forte } \\
5\end{array}$} & \multirow{2}{*}{\begin{tabular}{|l} 
Ponto \\
forte \\
4 \\
\\
$X$
\end{tabular}} & \multirow{2}{*}{$\begin{array}{l}\text { Ponto } \\
\text { médio } \\
3\end{array}$} & \multirow{2}{*}{$\begin{array}{l}\text { Ponto } \\
\text { fraco } \\
2\end{array}$} & \multirow{2}{*}{$\begin{array}{l}\text { Ponto } \\
\text { muito } \\
\text { fraco } \\
1\end{array}$} \\
\hline 1 & $\begin{array}{l}\text { O salão possui Gestão de caixa bem } \\
\text { definido }\end{array}$ & & & & & \\
\hline 2 & $\begin{array}{l}\text { A Gerência possui padronização do } \\
\text { seu trabalho }\end{array}$ & $\mathrm{X}$ & & & & \\
\hline 3 & $\begin{array}{l}\text { Possui a divisão do trabalho em } \\
\text { cada setor }\end{array}$ & & & $\mathrm{X}$ & & \\
\hline 4 & $\begin{array}{l}\text { O regime interno é de conhecimento } \\
\text { de todos os envolvidos }\end{array}$ & & $\mathrm{X}$ & & & \\
\hline 5 & $\begin{array}{l}\text { Os Gerentes são qualificados na } \\
\text { área Administrativa }\end{array}$ & & & $\mathrm{X}$ & & \\
\hline 6 & $\begin{array}{l}\text { A empresa deixa claro seus } \\
\text { objetivos e política organizacional }\end{array}$ & & & $\mathrm{X}$ & & \\
\hline 7 & $\begin{array}{l}\text { A Gerência preocupa-se com a } \\
\text { imagem das atividades realizadas }\end{array}$ & & & & $\mathrm{X}$ & \\
\hline 8 & $\begin{array}{l}\text { Há controle e monitoramento das } \\
\text { atividades realizadas }\end{array}$ & & & $\mathrm{X}$ & & \\
\hline 9 & $\begin{array}{l}\text { Procuram estabilizar a imagem e a } \\
\text { reputação do salão aos stakeholders }\end{array}$ & $\mathrm{X}$ & & & & \\
\hline 10 & $\begin{array}{l}\text { Existe parcerias estratégicas para o } \\
\text { salão }\end{array}$ & & $X$ & & & \\
\hline \multicolumn{2}{|c|}{ TOTAL $(\Sigma)$} & 10 & 12 & 12 & 2 & 0 \\
\hline \multicolumn{2}{|r|}{ MÉDIA POR GRAU (POR COLUNA) } & 1 & 1,2 & 1,2 & 0,2 & 0 \\
\hline
\end{tabular}

RC: 101963

Disponível em: https://www.nucleodoconhecimento.com.br/administracao/empresasalao-ellen 
Fonte: Elaborado pelos autores com base na coleta de dados, 2021.

No quadro 1, é exibido os 10 aspectos críticos que tiveram maior relevância, baseando-se de acordo com os critérios da Gestão Administrativa. Cada item foi distribuído, e, conforme determinadas pontuações, teve-se como resultado o desempenho do setor.

A coleta das atividades da empresa se deu de acordo com a entrevista. Com isso podemos apontar que os itens 3, 5, 6, 7 e 8 são expostos como o setor falho dentro da organização, isto é, apresentam um rendimento de médio a fraco, o que reflete em uma pontuação de 3,6 de desempenho.

Após considerar todos os fatores estabelecidos acima, foi averiguado que a empresa Salão Ellen Nascimento apresenta maior necessidade de atenção na área de gestão do seu plano de negócio, e com base no monitoramento de seus serviços e produtos, concluiu-se que a utilização de ferramentas pode trazer benefícios à empresa. Em vista disso, o problema do estudo baseia-se em: Como a implementação de técnicas administrativas e tecnologias de gestão podem ser utilizadas em uma microempresa para seu melhor desenvolvimento?

\subsection{PLANEJAMENTO DE AÇÕES}

O planejamento de ações é um método com a intenção de atingir um objetivo em uma sequência cronológica de ações necessárias com base no plano de ação estabelecido.

Quadro 2 - Ações interventivas.

\begin{tabular}{|l|l|l|l|}
\hline Item & Ações Interventivas & Cronologia & $\begin{array}{l}\text { Custo } R \$ / \\
\text { mensal }\end{array}$ \\
\hline 01 & Aprendizagem de técnicas financeiras e & Outubro/2021 & 400,00 \\
\hline
\end{tabular}




\begin{tabular}{|l|l|l|l|}
\hline & $\begin{array}{l}\text { práticas de gestão de equipes em projetos } \\
\text { de co-working } .\end{array}$ & \\
\hline 02 & $\begin{array}{l}\text { Utilização de um software de gestão para } \\
\text { gerenciamento das operações do salão, }\end{array}$ & Outubro/2021 & 80,00 \\
\hline 03 & Uso de marketing digital. & Outubro/2021 & 200,00 \\
\hline TOTAL: & & & 680,00 \\
\hline
\end{tabular}

Fonte: Elaborado pelos autores, 2021

As ações interventivas listadas acima são os primeiros passos que o gestor do salão Ellen Nascimento deve seguir para a melhora da administração de seu negócio e melhor controle de ações.

\subsection{FERRAMENTA 5W2H}

A ferramenta $5 \mathrm{~W} 2 \mathrm{H}$ foi utilizada para fazer as intervenções propostas. Essa ferramenta tem o intuito de auxiliar na execução do plano de ações dentro da organização, para que ele possa ser cumprido com clareza e eficiência, e guia o administrador por meio de perguntas, como: o que será feito? (What); por quê? (Why); onde? (Where); quando? (When); por quem? (Who); como será feito (How) e quanto irá custar? (How much).

O plano de ações de uma empresa tem uma importância muito grande. Dentro de uma micro ou pequena empresa, cumprir prazos, responsabilidade e gerir recursos técnicos e financeiros são extremamente importantes e relevantes, por isso a importância do uso da ferramenta de gestão $5 \mathrm{~W} 2 \mathrm{H}$, que possibilita esse controle e auxílio de ações (DERMONI, 2021).

O uso do método consiste em fazer perguntas objetivas que visam obter informações ímpares que servirão de apoio ao planejamento e na implementação das ações interventivas de uma forma geral, por isso, mediante as tabelas, ao ser utilizado a ferramenta $5 \mathrm{~W} 2 \mathrm{H}$ é possível criar um plano de ação específico com um acompanhamento mais amplo do projeto da empresa (DAYCHOUM, 2013).

RC: 101963

Disponível em: https://www.nucleodoconhecimento.com.br/administracao/empresasalao-ellen 


\subsubsection{APRENDIZAGEM DAS TÉCNICAS FINANCEIRAS}

Tanto para um gestor de grandes multinacionais quanto para um gestor de micro ou pequena empresa, ter o domínio de suas finanças é essencial para a sobrevivência da organização, pois a má gestão de recursos financeiros pode ser o responsável pela falência da empresa.

Quadro 3 - 5W2H, aprendizagem de técnicas financeiras

\begin{tabular}{|l|l|l|}
\hline Pergunta & \multicolumn{2}{|l|}{ Aprendizagem de técnicas financeiras } \\
\hline What & O que? & $\begin{array}{l}\text { Aprendizagem de técnicas financeiras e práticas de gestão } \\
\text { de equipes em projetos de co-working }\end{array}$ \\
\hline Why & Por quê? & Melhorar o desempenho financeiro \\
\hline Where & Onde? & Salão Ellen Nascimento \\
\hline When & Quando? & Outubro - 2021 \\
\hline Who & Quem? & Gestor \\
\hline How & Como? & Por meio de livros, artigos e vídeos. \\
\hline How & Quanto? & $\mathrm{R} \$ 400,00$ \\
\hline much & & \\
\hline
\end{tabular}

Fonte: Elaborado pelos autores, 2021

Com o domínio de algumas técnicas financeiras para auxiliar o gestor da organização, se pode começar a melhor orientar o gestor a direcionar as ações. Com o controle de suas finanças o gestor pode visualizar com mais clareza todos os resultados financeiros da microempresa e pode tomar as melhores decisões.

\subsubsection{UTILIZAÇÃO DE SOFTWARE}

O avanço da tecnologia em diversas áreas deixa o mercado mais competitivo, portanto, não seria diferente com a área administrativa das organizações. Por isso o uso de um software para organizar, criar um banco de dados, controlar recursos, entre outras funções, é quase que obrigatório para sobreviver no mercado

RC: 101963

Disponível em: https://www.nucleodoconhecimento.com.br/administracao/empresasalao-ellen 
competitivo, pois com o auxílio da tecnologia o gestor pode analisar os dados coletados e tomar decisões que mais favoreçam sua empresa.

Quadro 4 - 5W2H, utilização de software

\begin{tabular}{|l|l|l|}
\hline Pergunta & \multicolumn{2}{|l|}{ Utilização do software (AVEC) } \\
\hline What & O que? & $\begin{array}{l}\text { Utilização de um software de gestão para gerenciamento das } \\
\text { operações do salão }\end{array}$ \\
\hline Why & Por quê? & Auxiliar na gestão da organização \\
\hline Where & Onde? & Salão Ellen Nascimento \\
\hline When & Quando? & Outubro - 2021 \\
\hline Who & Quem? & Gestor / colaboradores \\
\hline How & Como? & Por meio de assinaturas para utilização da plataforma \\
\hline How & Quanto? & $\mathrm{R} \$ 80,00$ mensais \\
\hline Much & & \\
\hline
\end{tabular}

Fonte: Elaborado pelos autores, 2021

A utilização desse software irá auxiliar na parte de gestão e finanças, pois fornece relatórios, gráficos e tabelas que auxiliarão na visualização da empresa como um todo, na captação de recursos e despesas e na relação com o cliente, pois o software também auxilia no agendamento de clientes, evitando filas de longa espera, tornando o trabalho dos colaboradores mais efetivo e prezando pela satisfação do cliente.

\subsubsection{USO DO MARKETING DIGITAL}

O avanço e popularização das redes sociais deu-se principalmente entre os microempreendedores. Um importante veículo de comunicação como a plataforma do Instagram, em que passam milhares de pessoas todos os dias, torna-se uma grande vitrine, e, com um público-alvo bem definido, o alcance das publicações se torna muito alto e a captação de clientes se torna cada vez mais rápida.

RC: 101963

Disponível em: https://www.nucleodoconhecimento.com.br/administracao/empresasalao-ellen 
Quadro 5 - 5W2H, uso do marketing digital

\begin{tabular}{|l|l|l|}
\hline Pergunta & Uso do marketing digital (Instagram) \\
\hline What & O que? & Melhorar o marketing nas redes sociais \\
\hline Why & Por que? & Aumentar a captação de clientes \\
\hline Where & Onde? & Salão Ellen Nascimento \\
\hline When & Quando? & Outubro - 2021 \\
\hline Who & Quem? & Gestor / colaboradores \\
\hline How & Como? & Por meio da plataforma do Instagram \\
\hline How & Quanto? & $\mathrm{R} \$ 200,00$ mensais \\
\hline much & & \\
\hline
\end{tabular}

Fonte: Elaborado pelos autores, 2021

O marketing dentro das redes sociais tem um poder muito grande de aquisição de cliente e, por esse motivo, essa ferramenta deve ser utilizada depois das outras já citadas, pois o alcance dessas plataformas oferece uma grande visibilidade para a organização que a utiliza, porém, é necessário que o marketing esteja bem estruturado para receber esses novos clientes.

\section{CONSIDERAÇÕES FINAIS}

Diante da análise do estudo na empresa Salão Ellen Nascimento, verificou-se, por meio do diagnóstico organizacional, que o setor com maior índice crítico era o de administração, o departamento mais importante e que precisa atuar de forma presente na empresa, pois uma das principais causas de falência de microempresas é a má administração.

O objetivo desta pesquisa foi apresentar novas técnicas administrativas aos microempreendedores e como o uso da tecnologia pode auxiliar o gestor. Pode-se afirmar que a eficiência da microempresa melhorou muito com a utilização de um software, em relação ao controle de ações e recursos da empresa. As redes sociais 
também foram de extrema importância para a empresa, pois realizaram um papel fundamental na aquisição de clientes. E, por fim, organização financeira deixou tudo mais claro e tornou mais fácil tomar decisões importantes.

O estudo elaborado salientou a pergunta problema: Como a implementação de técnicas administrativas e tecnologias de gestão podem ser utilizadas em uma microempresa para seu melhor desenvolvimento? O estudo obteve o êxito esperado ao apresentar, por meio de propostas de ações interventivas, a aplicação de ferramentas administrativas dentro de uma microempresa, por meio de treinamentos voltados para gestão de empresas no sistema de co-work. Também foram apresentados recursos de software, com o objetivo de trazer praticidade, melhorar o entendimento e facilitar o trabalho do gestor da microempresa. Com isso, a administração da organização tornou-se mais eficiente e conseguiu desenvolver novos meios para resolver e criar soluções para os problemas mais facilmente.

O uso correto das ferramentas tecnológicas proporcionou melhorias significativas para a gerência da empresa, e ferramentas como o software foram de extrema importância para tais melhorias, tanto nos processos e na administração quanto na relação dos clientes com o salão Ellen Nascimento.

Uma microempresa estruturada administrativamente, que utiliza recursos tecnológicos a seu favor e faz uso das redes sociais como um mecanismo de aquisição de clientes, se destaca de outras microempresas e cria uma boa vantagem competitiva, o que a coloca em um patamar diferente das demais concorrentes. E foi o que ocorreu com o salão Ellen Nascimento, que por meio de pesquisas e ações interventivas, se tornou bem-organizado e relevante no mercado.

Em conclusão, por meio desse estudo de caso, verificou-se a importância da administração em uma microempresa e a relevância do próprio micro empreendimento para o mercado nacional, já que essas organizações acabam por gerar riqueza e empregos para milhões de brasileiros. 
Portanto, dar atenção a essa classe de empresas é importante para o mercado nacional, uma vez que investir em pesquisas mais aprofundadas em técnicas de inovações tecnológicas para microempresas, em administração para microempreendedores, no desenvolvimento e na evolução de setores de micro e pequenas empresas, contribuirá e muito para o desenvolvimento comercial e econômico do país.

\section{REFERÊNCIAS BIBLIOGRÁFICAS}

ALVES, M. Como escrever teses e monografias: um roteiro passo a passo. Rio de Janeiro: Elsevier Editora Ltda, 2013.

BARBOSA, F. V.; REIS, I. C. da. S. Finanças Comportamentais: os efeitos de certeza e reflexão nos processos decisórios em finanças e governança corporativa. Curitiba: Editora Aprris, 2021.

BATEMAN, T. S.; SNELL, S. A. Administração. São Paulo: McGraw Hill Brasil, 2013.

BERTOLINI, S. M. M. G. Pesquisa científica: do planejamento à divulgação. Jundiaí: Paco Editora, 2016.

BURGELMAN, R. A.; CRISTENSEN, C. M.; WHEELWRIGHT, S. C. Gestão estratégica da tecnologia e da inovação: conceito e soluções. New York: AMGH Editora, 2013.

CARDANO, M. Manual de pesquisa qualitativa: a contribuição da teoria da argumentação. Rio de Janeiro: Vozes Ltda, 2017.

CARVALHO, L. O. R. Et al. Metodologia científica: teoria e aplicação na educação a distância. Petrolina: Fundação UNIVASF, 2019.

CARVALHO, L.; KUBICA, F. Básico em Administração. São Paulo: Editora SENAC São Paulo, 2017.

RC: 101963

Disponível em: https://www.nucleodoconhecimento.com.br/administracao/empresasalao-ellen 
CHINEM, R. Marketing e divulgação da pequena empresa: como o pequeno e o microempresário podem chegar à mídia. São Paulo: Editora SENAC São Paulo, 2017.

CONTROLLE. Gestão financeira para microempresas: Para quem quer criar um negócio de alto potencial de crescimento. Controlle, 2014.

DAYCHOUM, M. 40+10 ferramentas e técnicas de gerenciamento. Rio de Janeiro: Brasport, 2013.

DERMONI, E. Fatores críticos de sucesso na gestão de pequenos negócios com base na Teoria $U$ : descubra como aplicar uma gestão de sucesso em pequenas empresas com o uso da Teoria $U$, que permite lucrar e crescer, apesar da crise. Belo Horizonte: Editora Dialética, 2021.

DIAS, V. B.; SANTOS, A. R.; SOUZA, G. Metodologia da pesquisa científica: a construção do conhecimento e do pensamento científico no processo de aprendizagem. Porto Alegre: Animal, 2013.

GERRING, J. Pesquisa de estudo de caso: práticas e princípios. Rio de Janeiro: Editora Vozes, 2019.

HERTER, M.; LEAL, C.; SOARES, R. R. Marketing: um desafio incontornável para as microempresas. Lisboa: Actual, 2019.

MORAES, C. A. Na trilha da produção científica em administração de 1979 a 2017. Curitiba: Appris, 2020.

RODRIGUES, T. K. de. A. Ferramentas de gestão nas microempresas brasileiras. Jundiaí: Paco e Littera, 2014.

CAUCHIK, P. A. et al. Projeto do produto. Rio de Janeiro: Elsevier Brasil,2013. 
SAKAMOTO, C. K.; SILVEIRA, I. O. Como fazer projetos de iniciação científica. São Paulo: Paulus Editora, 2019.

SEBRAE, Micro e pequenas empresas geram 27\% do PIB do Brasil. 2020. Disponível em: https://www.sebrae.com.br/sites/PortalSebrae/ufs/mt/noticias/micro-epequenas-empresas-geram-27-do-pib-dobrasil,ad0fc70646467410VgnVCM2000003c74010aRCRD. Acesso em: 16 set. 2021

SENHORAS, E. M. Administração: estudos organizacionais e sociedade. Ponta Grossa: Atena Editora, 2021.

SERIES, B. E. Administração financeira - série essencial. $3^{\underline{a}}$ ed. São Paulo: Editora Saraiva, 2017.

SEVERINO, A. J. Metodologia do trabalho científico. São Paulo: Cortez Editora, 2014.

ZANELLA, L. C. H. Metodologia de pesquisa. Florianópolis: Departamento de Ciências da Administração/UFSC, 2013.

Enviado: Outubro, 2021.

Aprovado: Novembro, 2021. 